Case Reports
in Dermatology

Case Rep Dermatol 2020;12:225-230

\title{
Drug Reaction with Eosinophilia and Systemic Symptoms (DRESS) Associated with Mycoplasma pneumoniae Infection
}

\author{
Guy Shalom ${ }^{a, b}$ Raed Khoury a,b Amir Horeva, c \\ aFaculty of Health Sciences, Ben-Gurion University of the Negev, Beer-Sheva, Israel; \\ ${ }^{\mathrm{b}} \mathrm{Clalit}$ Health Services, Tel-Aviv, Israel; 'Pediatric Dermatology Service, Soroka University \\ Medical Center, Beer-Sheva, Israel
}

\section{Keywords}

Adverse drug reaction - Drug eruption - Drug reaction with eosinophilia and systemic symptoms (DRESS) $\cdot$ Mycoplasma $\cdot$ Infection $\cdot$ Interferon $-\gamma$ release test

\begin{abstract}
Mycoplasma infection may lower the threshold for drug allergy in particular patients. We present a case of drug reaction with eosinophilia and systemic symptoms (DRESS), with drug etiology and non-drug etiology (Mycoplasma infection). Possible synergism between previously known drug allergy and the acute Mycoplasma infection may have led to DRESS eruption. Interferon- $\gamma$ release test and TNF- $\alpha$ release test yielded different patterns in the present case, suggesting a different role for each in different drug eruption types.
\end{abstract}

\section{Case Report}

A 19-year-old female with an unremarkable medical history, and known drug allergy to penicillin since infancy, was admitted to our department. She suffered from a severe cutaneous eruption, following treatment with cephalosporin for tonsillitis. Her initial treatment was 


\section{Case Reports in Dermatology}

Case Rep Dermatol 2020;12:225-230

DOI: $10.1159 / 000510706$

C 2020 The Author(s). Published by S. Karger AG, Basel www.karger.com/cde

Shalom et al.: Drug Reaction with Eosinophilia and Systemic Symptoms (DRESS) Associated with Mycoplasma pneumoniae Infection

cephalexin (tablet; Cefovit ${ }^{\circledR}$ ) $250 \mathrm{mg} \times 4 /$ day. Two days later, the patient developed mild cutaneous eruption, and the treatment was replaced by cefuroxime (tablet; Zinnat ${ }^{\circledR}$ ) $500 \mathrm{mg}$ $\times 2$ /day. Under this treatment regimen, her cutaneous eruption was aggravated; thus, the patient was referred to our institution. Physical examination revealed a widespread heterogenic eruption with papular, pustular, erythema target-like lesions and Sweet-like lesions (Fig. 1a, b). Marked facial edema was noted (Fig. 1c). The estimated body surface area involvement was more than 50\%. Mild oral erosions were present without any other mucosal involvement. Nikolsky's sign was negative. The patient had a fever of $39^{\circ} \mathrm{C}$ and bilateral cervical and submandibular lymphadenopathy, larger than $1 \mathrm{~cm}$ on palpation. Respiratory auscultation demonstrated bilateral crackles present on both lung bases. A chest X-ray revealed bilateral infiltrates present in both lung bases. Laboratory tests: complete blood count performed upon her admission revealed anemia of $9.3 \mathrm{~g} / \mathrm{dL}$, leukocytosis of 30,350 cells $/ \mu \mathrm{L}$, and eosinophilia of 930 cells $/ \mu \mathrm{L}$. The patient had $2 \%$ atypical lymphocytes on her peripheral blood smear test. Her creatinine level, liver function tests, and electrolytes were within normal limits, while her albumin level was $2 \mathrm{~g} / \mathrm{dL}$. Other ancillary tests revealed hypocomplementemia C3 level of 57 (90-180) and C4 of 4 (10-40). Screening tests for collagen vascular diseases were negative for ANA and RF. Thyroid function tests at baseline were normal. Laboratory investigation screening for viral infections including human herpes virus-6, EBV, CMV, adenovirus, Coxsackie A virus, hepatitis viruses, and varicella zoster virus were all negative. Serologic screening for bacterial infection demonstrated positive IgM and negative IgG for Mycoplasma pneumoniae. Sequential Mycoplasma serology test done 10 days from index day revealed seroconversion: positive for IgM and IgG anti-M. pneumoniae antibodies. Histopathologic examination supported the diagnosis of drug eruption, demonstrating several necrotic keratinocytes in the epidermis, vacuolar changes with interface dermatitis, and an extensive papillary edema (Fig. 2a, b). Perivascular and interstitial mononuclear infiltrate was present admixed with numerous eosinophils (Fig. 2c). Upon her admission, treatment with cefuroxime (tablet; Zinnat ${ }^{\circledR}$ ) was discontinued and switched to intravenous azithromycin. Simultaneous treatment with prednisone $60 \mathrm{mg} \times 1 /$ day was initiated together with topical corticosteroids. Under this treatment regimen, with gradual tapering down of prednisone, a slow, steady improvement was noticed. Five weeks after initiating this treatment regimen, the patient gained complete resolution. One year following her remission, the patient underwent a patch test for drug series (Cutaneous Adverse Drug Reaction Series CAD-1000), which was negative. In vitro tests for cefuroxime (tablet; Zinnat ${ }^{\circledR}$ ), penicillin (tablet; Moxypen ${ }^{\circledR}$ ), and cephalexin (tablet; Cefovit $^{\circledR}$ ) were performed 1 year following the remission, supporting drug reaction with eosinophilia and systemic symptoms (DRESS) diagnosis (Fig. 3).

\section{Discussion}

Our patient presented with two major medical problems that are closely related: on the one hand, acute M. pneumoniae infection, a diagnosis that was established clinically ("tonsillitis," systemic symptoms, fever, crackles by auscultation, bilateral lung infiltrate by CXR, and compelling serology tests) and on the other hand, the patient suffered severe drug eruption based on her past medical history (cephalosporin treatments in a patient with penicillin allergy may raise the possibility of cross-reactivity), positive withdrawal test, and positive in vitro tests. Nevertheless, these two problems are probably related. Cutaneous manifestations of Mycoplasma infection include a wide clinical spectrum from exanthematous eruption, erythema multiforme (EM), urticaria, and erythema nodosum to the less common forms of mu- 


\section{Case Reports in Dermatology}

Case Rep Dermatol 2020;12:225-230

DOI: 10.1159/000510706

(c) 2020 The Author(s). Published by S. Karger AG, Basel www.karger.com/cde

Shalom et al.: Drug Reaction with Eosinophilia and Systemic Symptoms (DRESS) Associated with Mycoplasma pneumoniae Infection

cositis and Sweet's syndrome [1-3]. M. pneumoniae-induced rash and mucositis is a relatively recent entity, usually seen in children and young adults. It is characterized by pronounced mucositis, scant or absent cutaneous involvement and generally good prognosis [4]. The current case is characterized by extensive skin and mild mucous membrane involvement, histologic and in vitro test results, as well as the long course of the disease, making M. pneumoniaeinduced rash and mucositis diagnosis less favorable. Stevens-Johnson syndrome and toxic epidermal necrolysis are frequently reported to be associated with Mycoplasma infection [5]; nonetheless, drug eruption with systemic symptoms (DRESS) is not commonly reported in association with M. pneumoniae infection as demonstrated in the present case [6]. According to the DRESS validation score established by the REGISCAR group [7], our patient has probable DRESS (4-point score) upon her admission: fever, eosinophilia, atypical lymphocytes, extent $>50 \%$, rash suggesting DRESS, in the presence of positive serology for Mycoplasma and negative serologies and blood cultures [7]. The association between DRESS and cephalosporins, as in our case, has been given more attention in the last few years [8, 9]. The EM-like morphology in DRESS is associated with more severe liver involvement [10]; interestingly, our patient had entirely normal liver functions; oral erosions are more compatible with the mycoplasma infection EM variant, hinting for a possible EM-DRESS overlap syndrome. However, a short latency period of less than 5 days, which is allegedly non-consistent with DRESS diagnosis, can be explained by previously known sensitivity to penicillin and a possible crossreaction, suggesting a lowered threshold for drug allergy and cross-reaction in the presence of Mycoplasma infection. Patch tests are not highly sensitive in the case of DRESS eruptions. Thus, negative results do not rule out this option. In vitro tests supported DRESS diagnosis, incriminating cefuroxime (Zinnat ${ }^{\circledR}$ ) more strongly than cephalexin (Cefovit ${ }^{\circledR}$ ) as the culprit drug. Interestingly, TNF- $\alpha$ release was significantly increased following exposure to penicillin (Mxypen ${ }^{\odot}$ ) and cefuroxime (Zinnat ${ }^{\circledR}$ ) but not to cephalexin (Cefovit ${ }^{\circledR}$ ), while interferon- $\gamma$ release test was significantly positive for all three. This observation may hint at the different roles of TNF- $\alpha$ and interferon- $\gamma$. Nevertheless, a general conclusion regarding the role of TNF$\alpha$ in the pathophysiology of DRESS cannot be made on a solid ground based on a single observation.

In conclusion, we presented a case of DRESS, with drug etiology and non-drug etiology (bacterial infection). Each of these can serve as a sole etiology for the cutaneous eruption in the present case, yet possible synergism between the two is reasonable. M. pneumoniae infection may lower the threshold for drug allergy in this particular patient with penicillin allergy, triggering a cross-reaction between cephalosporin and penicillin.

\section{Acknowledgment}

The authors thank Prof. Sima Halevy.

\section{Statement of Ethics}

The patient gave written informed consent for the publication of her case (including publication of images). The research was conducted ethically in accordance with the World Medical Association Declaration of Helsinki. 


\section{Case Reports in Dermatology}

\section{Conflict of Interest Statement}

The authors have no conflicts of interest to declare.

\section{Funding Sources}

None.

\section{Author Contributions}

G.S. collected the data and wrote the initial manuscript draft. R.K. collected the data and revised the manuscript. A.H. evaluated and critically revised the manuscript and is the corresponding author. All authors provided critical feedback and contributed to the final version of the manuscript.

\section{References}

1 Atkinson TP, Balish MF, Waites KB. Epidemiology, clinical manifestations, pathogenesis and laboratory detection of Mycoplasma pneumoniae infections. FEMS Microbiol Rev. 2008 Nov;32(6):956-73.

2 Schalock PC, Dinulos JG. Mycoplasma pneumoniae-induced cutaneous disease. Int J Dermatol. 2009 Jul; 48(7):673-80.

3 Cherry JD. Anemia and mucocutaneous lesions due to Mycoplasma pneumoniae infections. Clin Infect Dis. 1993 Aug; 17(Suppl 1):S47-51.

4 Norton SA. Diagnosing Mycoplasma pneumoniae-induced rash and mucositis (MIRM) in the emergency room. J Am Acad Dermatol. 2015 Aug;73(2):e67.

5 Tay YK, Huff JC, Weston WL. Mycoplasma pneumoniae infection is associated with Stevens-Johnson syndrome, not erythema multiforme (von Hebra). J Am Acad Dermatol. 1996 Nov;35(5 Pt 1):757-60.

6 Kosseian-Bal I, Bocquet H, Beneton N, Encaoua R, Deforges L, Roujeau JC, Revuz J. Hypersensitivity syndrome during Mycoplasma pneumoniae infection. Ann Dermatol Venereol. 1998;125(5):328-30.

7 Kardaun S, Sidoroff A, Valeyrie-Allanore L, Halevy S, Davidovici BB, Mockenhaupt M, Roujeau JC. Variability in the clinical pattern of cutaneous side-effects of drugs with systemic symptoms: does a DRESS syndrome really exist? Br J Dermatol. 2007;156:609-11.

8 Babu T, Panachiyil GM, Sebastian J, Shastry V. Drug Rash With Eosinophilia and Systemic Symptoms (DRESS) Syndrome Probably Related to Cefpodoxime: A Case Report. J Pharm Pract. 2019 Aug 5:897190019866094.

9 Karakayalı B, Yazar AS, Çakir D, Cetemen A, Kariminikoo M, Deliloglu B, et al. Drug Reaction with Eosinophilia and Systemic Symptoms (DRESS) syndrome associated with cefotaxime and clindamycin use in a 6 year-old boy: a case report. Pan Afr Med J. 2017 Nov;28:218.

10 Walsh S, Diaz-Cano S, Higgins E, Morris-Jones R, Bashir S, Bernal W, et al. Drug reaction with eosinophilia and systemic symptoms: is cutaneous phenotype a prognostic marker for outcome? A review of clinicopathological features of 27 cases. Br J Dermatol. 2013 Feb;168(2):391-401. 


\section{Case Reports in Dermatology}

(c) 2020 The Author(s). Published by S. Karger AG, Basel www.karger.com/cde

Shalom et al.: Drug Reaction with Eosinophilia and Systemic Symptoms (DRESS) Associated with Mycoplasma pneumoniae Infection

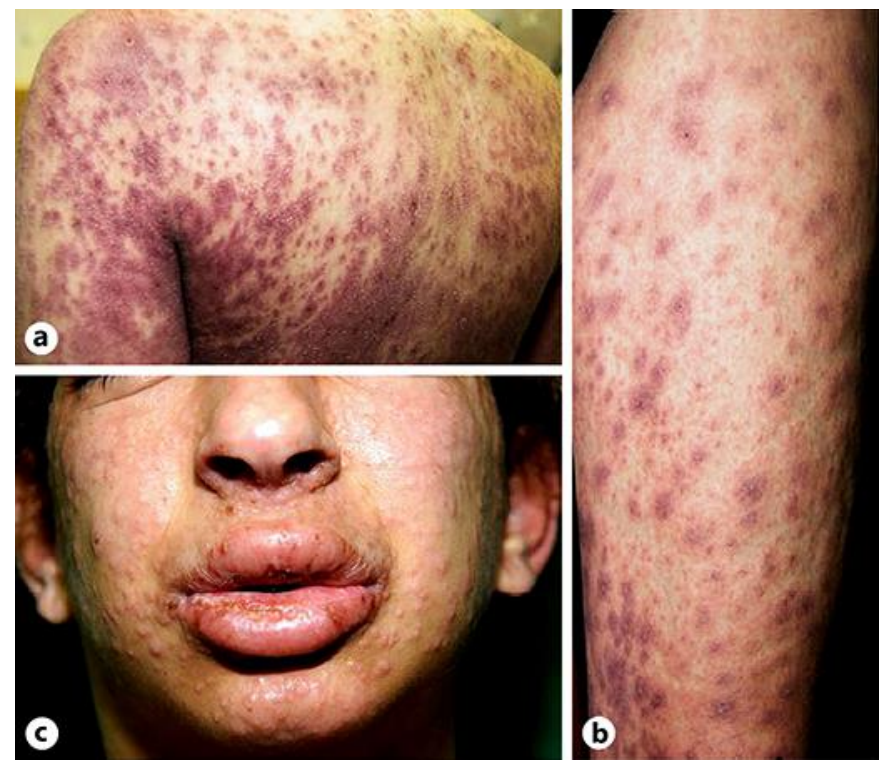

Fig. 1. a Papular, pustular, erythema, and target-like lesions over the trunk. b Papular, pustular, and targetlike lesions over the right thigh. c Marked face edema, Sweet-like lesions, and mild oral mucosal involvement.
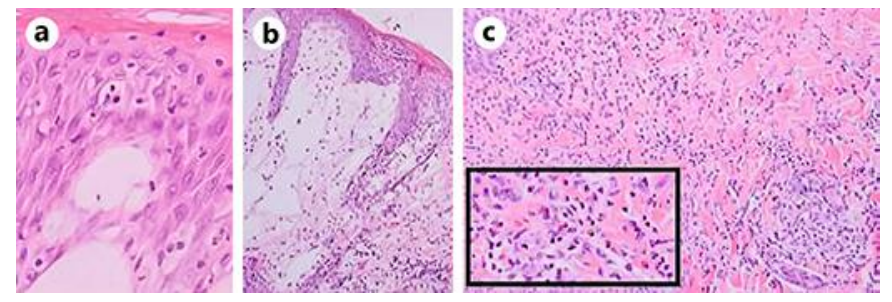

Fig. 2. a Necrotic keratinocytes in the epidermis, vacuolar changes, interface dermatitis in the basal layer (H\&E, magnification $\times 360$ ). $\mathbf{b}$ Extensive papillary edema $(H \& E$, magnification $\times 360)$. c Perivascular and interstitial mononuclear infiltrate was present admixed with numerous eosinophils (inset) (H\&E, magnification $\times 360$ ). 


\section{Case Reports in Dermatology}

a

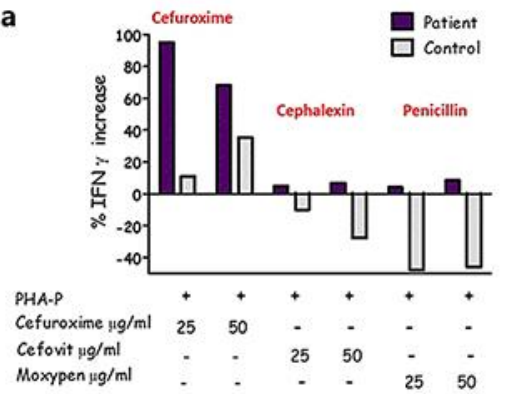

Case Rep Dermatol 2020;12:225-230

DOI: $10.1159 / 000510706$ (C) 2020 The Author(s)
www.karger.com/cde

Shalom et al.: Drug Reaction with Eosinophilia and Systemic Symptoms (DRESS) Associated with Mycoplasma pneumoniae Infection b

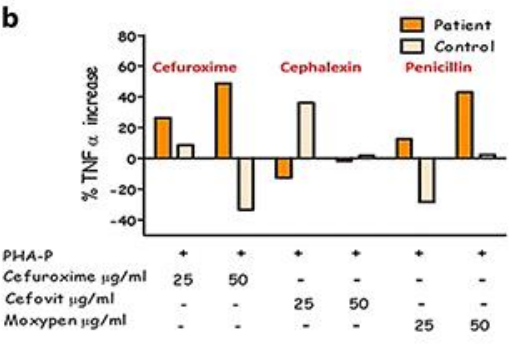

Fig. 3. In vitro tests for cephalexin cefuroxime and penicillin 1 year following the remission. The patient and healthy control subject with no known drug sensitivity: interferon- $\gamma$ release test (a) and TNF- $\alpha$ release test (b). 